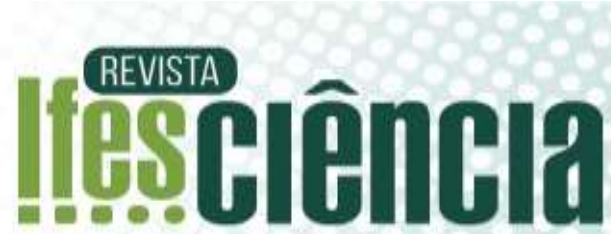

\section{EVASÃO NA EDUCAÇÃO A DISTÂNCIA: AS CAUSAS DO ABANDONO EM UM CURSO DE PÓS-GRADUAÇÃO LATO SENSU}

\author{
EVASION IN DISTANCE EDUCATION: THE CAUSES OF DROPOUT IN A \\ POSTGRADUATE COURSE
}

\author{
Vinícius Delfino Silva ${ }^{1 *}$ \\ Marize Lyra Silva Passos ${ }^{2}$ \\ Isaura Alcina Martins Nobre ${ }^{3}$
}

\begin{abstract}
${ }^{1}$ Secretaria Estadual de Educação do Estado Espírito Santo. E-mail: viniciusdelfinosilva@ gmail.com.
${ }^{2}$ Instituto Federal do Espírito Santo. E-mail: marize@ ifes.edu.br.

${ }^{3}$ Instituto Federal do Espírito Santo. E-mail:isaura.ead@gmail.com.
\end{abstract}

Artigo submetido em 09/03/2019, aceito em 09/09/2019 e publicado em 23/12/2019.

Resumo: Apesar do crescimento da educação a distância nos últimos anos, as alta taxas de evasão discente preocupam as instituições de ensino, pois resultam em ociosidade de profissionais, de materiais e de espaço físico. Tal fenômeno foi detectado em um curso de pós-graduação lato sensu oferecido em instituição pública de ensino superior no Brasil, que apresenta evasão média de 41,23\% nas cinco edições já ofertadas. Nesse sentido, o presente trabalho apresenta como objetivo investigar as causas associadas à evasão discente, identificando interferências internas e externas ao contexto da especialização que levaram a essa situação. Esta pesquisa baseou-se no procedimento técnico survey e teve um enfoque quali-quantitativo, utilizando como instrumento de coleta de dados um questionário enviado por e-mail aos 334 alunos evadidos do curso. Obteve-se 66 respondentes, equivalente a um retorno de $19,76 \%$. A análise dos dados demonstrou que as principais causas relacionadas à evasão discente foram: a falta de tempo para estudar, carga horária semanal de trabalho (externas); complexidade das atividades, prazos de entrega das mesmas e didática dos professores (internas). Portanto, estratégias de combate à evasão devem ser adotadas pela instituição a fim de minimizar o desperdício de recursos públicos.

Palavras-chave: Evasão; educação a distância; educação superior.

Abstract: Despite the growth of distance education in recent years, the high dropout rates worry the educational institutions, because they result in idleness of professionals, materials, and physical space. This phenomenon was detected in a postgraduate course offered at a public higher education institution in Brazil, which has an average dropout rate of $41.23 \%$ in the five editions already offered. In this sense, the present work aimed to: investigate the causes associated with student dropout, identifying internal and external interference with the context of specialization that led to this situation. This research was based on the technical survey procedure and used Multi-Qualitative Research Method Approaches. For this, we used as a data collection instrument a questionnaire sent by email to the 334 students evaded from the course. We obtained 66 respondents, equivalent to a return of $19.76 \%$. Data analysis showed that the principal causes related to student dropout were: lack of time to study, weekly workload (external); the complexity of activities, delivery times and didactics of teachers (internal). Therefore, strategies to combat evasion should be adopted by the institution in order to minimize the waste of public resources.

Keywords: Evasion; dropout; distance education; higher education. 


\section{INTRODUÇÃO}

Em consequência da dimensão continental do território brasileiro, a Educação a Distância (EaD) torna-se alternativa viável ao proporcionar flexibilidade de tempo e espaço para aqueles que estão situados em regiões de difícil acesso aos centros de ensino ou para quem tem uma rotina de trabalho incompatível com a disponibilidade que os cursos presenciais exigem. A expansão da educação a distância deve-se, principalmente no interior do país, a implementação das políticas governamentais, como o sistema UAB (Universidade Aberta do Brasil), que foi criado pelo Decreto $n^{\circ} 5.800$, de 8 de julho de 2006, que em seu Artigo $1^{\circ}$ diz que o Sistema Universidade Aberta do Brasil é um sistema "[...] voltado para o desenvolvimento da modalidade de educação a distância, com a finalidade de expandir e interiorizar a oferta de cursos e programas de educação superior no País" (BRASIL, 2006).

Apesar do crescimento da $\mathrm{EaD}$ nos últimos anos, a alta taxa de evasão discente preocupa as instituições de ensino. Segundo o Censo EAD.BR de 2018 (ABED, 2018, p. 71), “[...] as taxas de evasão em EAD estão cada vez mais próximas daquelas dos cursos presenciais. [...]". Contudo apesar dessas taxas "[...] as instituições de ensino não conhecem os motivos da evasão. Entre os cursos regulamentados totalmente a distância, $59 \%$ das instituições respondem que não sabem os motivos ou não respondem à questão [...]" (ABED, 2018, p. 10). O Censo demonstra que as Instituições Educacionais Públicas Federais apresentam, em sua maioria, uma taxa de evasão na $\mathrm{EaD}$ na faixa de $26 \%$ a $50 \%$.

Como descrito por Woodley e Simpson (2015), a evasão é o "elefante na sala", porque o problema é bem grande e, como visto anteriormente, muitas instituições não sabem o motivo dessa evasão. A desistência dos cursos a distância é perceptível e preocupante em todos os níveis de ensino. Dessa forma, a razão em discutir e pesquisar sobre uma temática tão complexa motivou esta pesquisa. Sendo, inclusive, esta a primeira pesquisa sobre o tema na Instituição.

Então, constatada a problemática e visando a responder essas inquietudes, o presente trabalho tem como objetivo investigar as causas associadas à evasão discente, identificando interferências internas e externas ao contexto da especialização que levaram a essa situação.

\section{A EVASÃO NO ENSINO SUPERIOR A DISTÂNCIA}

A evasão discente no ensino superior tem sido discutida em pesquisas desde a década de 1970, a exemplo citamos a contribuição de Tinto (1975). Desde então a temática passou a ser preocupação das instituições e órgãos responsáveis pela educação. Hoje, contudo, os estudos sobre a evasão se concentram mais ao ensino fundamental e médio, conforme Biazus (2004). Ainda segundo o autor, quando há trabalhos que abordam o tema acerca do ensino superior, eles são mais gerais, envolvem vários cursos de uma instituição, isto é, não se voltam para a evasão de um determinado curso.

Com o propósito de melhor compreender o fenômeno da evasão discente no ensino superior, faz-se necessário primeiramente uma conceituação. Nesse sentido, Fávero (2006) e Netto, Guidotti e Santos (2017) entendem a evasão como o movimento do aluno em desistir do curso após efetivada a matrícula, inclui-se nesse panorama aqueles que não chegam a se apresentar aos colegas e professores. Em suma, o aluno para ser considerado evadido pode ter abandonado o curso ou sido reprovado em alguma disciplina, neste caso o regimento do curso não permite a continuidade do mesmo, sendo o aluno automaticamente desligado do curso. 
A evasão é um fenômeno global e complexo, inerente às instituições de ensino e cursos de todos os níveis acadêmicos. Muitos estudos têm debatido sobre os seus possíveis fatores. Moore e Kearsley (2007) argumentam que há anos gestores e estudiosos têm se debruçado a fim de entender por que uma parte dos alunos evade de seus cursos. Espera-se, dessa forma, que o levantamento das causas proporcione a criação de estratégias com a finalidade de reduzir as taxas de insucesso.

No ensino superior a evasão é um problema que afeta o resultado de programas educacionais em diversos países. A perda de alunos que se matriculam, porém não concluem os cursos iniciados resultam em prejuízos imensuráveis no âmbito social, institucional e econômico. Enquanto no setor privado acarreta em déficit de receitas, no setor público, ocasiona em recursos públicos investidos sem o esperado retorno. Diante do exposto, Fialho e Prestes (2014) afirmam que as consequências causadas pela evasão afetam todos os sujeitos envolvidos no processo educacional, assim como influenciam o emocional, psicológico e o financeiro. Por conseguinte, acarreta em ausência de indivíduos qualificados para o mercado de trabalho, colaborando para o aumento das taxas de desemprego e, por sua vez, corroborando na expansão da desigualdade social no país.

Em virtude de uma das maiores vantagens da educação a distância, que é o livre arbítrio por parte do estudante na escolha do local e horário para estudar, a evasão torna-se mais suscetível se o aluno não for disciplinado, não conseguir se desvencilhar das inúmeras distrações do ambiente doméstico e estiver preso aos paradigmas da educação presencial. Então, o sucesso do aluno no curso pode depender de sua organização em dividir o tempo de maneira a evitar acumular muitos conteúdos, como enfatizam os autores:

\begin{abstract}
Quando se decide estudar nessa modalidade de ensino é extremamente importante a atenção que se dispensa ao estabelecimento de objetivos de estudo, pois é a partir disso que é possível listar prioridades e organizar o tempo com as demandas do curso [...]. Assim, o aluno que determina objetivos de estudo, tendo uma noção clara daquilo que quer (do programa acadêmico e do curso em si) e organiza o seu tempo para leituras de materiais, tempo online para realização de atividades, trabalhos em grupo etc., provavelmente terá sucesso num curso a distância (NETTO; GUIDOTTI; SANTOS, 2017, n.p).
\end{abstract}

A evasão na $\mathrm{EaD}$ é tratada com preocupação, como pode ser visto no Censo EAD.BR (referente ao ano de 2017) "[...] um dos principais problemas enfrentados pela $\mathrm{EAD}$, para o qual não é possível identificar uma causa única" e que não há soluções fáceis para o problema. Inclusive autores como Woodley e Simpson (2015) propõem que o tema seja incorporado a uma agenda de pesquisa internacional.

A complexidade do fenômeno da evasão, em razão das inúmeras variáveis, torna o trabalho de determinar o porquê do aluno evadir, mais difícil (BIAZUS, 2004; BITTENCOURT; MERCADO, 2012). Dessa maneira, a implementação de programas para combate à evasão nos cursos na modalidade a distância seria um passo largo frente ao combate do problema em questão.

Conforme a literatura consultada, estudos apontam diferentes causas que influenciam a evasão nos cursos a distância no ensino superior: desenho do curso, ambiente próprio, habilidades tecnológicas do aluno e atividades do curso (CORNELIO; VASCONCELOS; GOULART, 2016); a falta de incentivo aos alunos pelo corpo docente, as dificuldades de aprendizagem e o pouco tempo dedicado aos estudos (REINO et al., 2015); a falta de tempo, motivos de saúde e 
pouca dedicação ao curso (OLIVEIRA; OESTERREICH; ALMEIDA, 2018).

Apesar das taxas de evasão serem sempre uma preocupação em qualquer nível e área de ensino, o Censo EAD.BR de 2018 (ABED, 2018) demonstra com surpresa que menos de $50 \%$ das instituições conheçam os motivos dessa evasão. Apesar desse desconhecimento, no Censo EAD.BR de 2017, algumas instituições citaram algumas das principais causas da evasão como sendo, a falta de tempo, questões financeiras e a não adaptação à modalidade $\mathrm{EaD}$, que aparece logo em seguida (ABED, 2017).

A falta de tempo é indicada como uma das principais causas da evasão discente. Embora a modalidade ofereça diversas vantagens, como o não deslocamento à instituição todos os dias, a flexibilização das jornadas de estudo de acordo com o trabalho e vida pessoal, é determinante a organização do tempo para o sucesso do estudante na sua trajetória num curso EaD. Afinal, essas vantagens tornam-se prejudiciais a depender do perfil do aluno, segundo Netto, Guidotti e Santos $(2017$, n.p) "[...] pode ser uma desvantagem para quem não consegue estabelecer horários de estudo e regras que estabeleçam uma organização para dedicação ao curso".

A falta de recursos financeiros dos estudantes, evidenciada pelas instituições de ensino e pelos próprios estudantes, é outro fator determinante da desistência nos cursos da modalidade a distância. Contudo, de acordo com os estudos, há uma simplificação nas respostas que apontam tal é (SILVA FILHO et al., 2007, p. 643):

[...] uma vez que as questões de ordem acadêmica, as expectativas do aluno em relação à sua formação e a própria integração do estudante com a instituição constituem, na maioria das vezes, os principais fatores que acabam por desestimular o estudante a priorizar o investimento de tempo ou financeiro, para conclusão do curso. Ou seja, ele acha que o custo benefício do "sacrifício" para obter um diploma superior na carreira escolhida não vale mais a pena.

O curso ofertado na modalidade educação a distância é vendido como uma alternativa mais barata em comparação com o presencial, o que configura um erro, pois conforme a afirmação de Netto et al. (2017, n.p):

[...] os custos das Instituições de Ensino são altos quando o objetivo é ofertar cursos na modalidade a distância com qualidade. É preciso um grande investimento em capacitação de professores, tutores, materiais de apoio, estrutura física e tecnológica, o que faz esta modalidade de ensino ter um custo elevado, mas que pode ser diluído, se bem administrado, com a reusabilidade de materiais em reedições de cursos.

A falta de adaptação à metodologia de cursos na educação a distância está, também, entre as principais causas relacionadas à evasão discente. $\mathrm{O}$ importante é a orientação inicial, de preferência antes de começar o curso, sobre a dinâmica da modalidade, do curso e da instituição. Muitos programas costumam ofertar uma disciplina no primeiro módulo exclusivamente com a finalidade de contextualizar o universo da $\mathrm{EaD}$ ao aluno, que em muitos casos não teve nenhuma experiência com a modalidade anteriormente. É importante por parte do estudante em estabelecer "objetivos de estudo", pois segundo Netto et al. (2017, n.p):

[...] é a partir disso que é possível listar prioridades e organizar o tempo com as demandas do curso. Assim, é necessário que o aluno seja claro ao estabelecer objetivos, tendo em mente que um curso a distância exige em média de 12 a 15 horas de estudos semanais, ou seja, é necessário um maior tempo de estudo do que o presencial $[\ldots]$. 
Entretanto, por considerar a evasão um fenômeno de natureza complexa, os estudos de Bittencourt e Mercado (2014) e de Abbad, Carvalho e Zerbini (2006) classificam as causas da evasão discente em dois grandes grupos: as causas internas e as causas externas ao contexto institucional.

As causas internas, apontadas por Bittencourt e Mercado (2014), estão ligadas ao aluno enquanto está na universidade, são elas: atitude comportamental, motivos institucionais e didático-pedagógicos. Essas categorias desdobram-se em subcategorias relacionadas às percepções do aluno dentro da instituição, a respeito da infraestrutura, corpo docente e assistência socioeducacional como podem ser vistos no Quadro 1.

Quadro 1: Causas internas a instituição que podem causar a evasão na EaD

\begin{tabular}{|c|c|}
\hline \multicolumn{2}{|c|}{ Atitude Comportamental } \\
\hline Didática dos professores & \multirow{5}{*}{$\begin{array}{l}\text { Parte do princípio que o aluno a distância é } \\
\text { diferente do presencial e o contato e a didática } \\
\text { dos professores e tutores tem que ser voltada e } \\
\text { focada no aluno. }\end{array}$} \\
\hline Orientação da coordenação do curso & \\
\hline Motivação e incentivo por parte do tutor & \\
\hline Insatisfação com o tutor & \\
\hline Contato com professores & \\
\hline \multicolumn{2}{|c|}{ Motivos Institucionais } \\
\hline $\begin{array}{l}\text { Estrutura dos polos de ensino (Laboratório de } \\
\text { informática, biblioteca) }\end{array}$ & \multirow{4}{*}{$\begin{array}{l}\text { Proporciona ao aluno condições para o estudo. } \\
\text { Com uma estrutura para que o aluno possa ter } \\
\text { acesso a bibliotecas e laboratórios. }\end{array}$} \\
\hline Interatividade no AVA & \\
\hline Meios de comunicação oferecidos para contato & \\
\hline AVA utilizado pelo curso & \\
\hline \multicolumn{2}{|c|}{ Requisitos Didático-Pedagógicos } \\
\hline Encontros presenciais & \multirow{8}{*}{$\begin{array}{l}\text { Estimula a cooperação e relação entre os } \\
\text { alunos do curso, estimulando uma criação } \\
\text { colaborativa que conceda subsídios para a } \\
\text { aprendizagem dos alunos. Deve possibilitar um } \\
\text { feedback imediato ao aluno sobre suas } \\
\text { atividades e ações no curso. Com o devido } \\
\text { retorno os tutores e professores podem } \\
\text { identificar as possíveis causas de erros nas } \\
\text { atividades. }\end{array}$} \\
\hline Complexidade das atividades & \\
\hline Contato entre colegas de cursos & \\
\hline Prazos de entrega das atividades & \\
\hline Feedback do tutor & \\
\hline Material didático oferecido & \\
\hline Qualidade do curso & \\
\hline Falha de elaboração do curso & \\
\hline
\end{tabular}

Fonte: Bittencourt e Mercado (2014, p. 475)

As causas externas estão diretamente relacionadas ao estudante, ou seja, são referentes aos motivos sociopolíticoeconômicos, vocação pessoal e circunstâncias individuais. As circunstâncias pessoais estão suscetíveis a mudarem drasticamente a vida do indivíduo, como mudança de interesse pessoal ou profissional, problemas familiares, relacionados à saúde e financeiros (JENSEN; ALMEIDA, 2009).
Portanto, o aluno da EaD deve saber gerir todas essas variações de forma equilibrada as circunstâncias que envolvam sua vida pessoal a fim de não prejudicar em seu desempenho no curso. As subcategorias das causas externas são divididas em três, que se subdividem em 15 motivos pelos quais os alunos poderão evadir do curso (BITTENCOURT; MERCADO, 2014), conforme Quadro 2. 
Quadro 2: Causas externas a instituição que podem causar a evasão na EaD

\begin{tabular}{|c|c|}
\hline \multicolumn{2}{|c|}{ Motivos Sócio Político-Econômicos } \\
\hline Apoio da instituição que trabalha & \multirow{5}{*}{$\begin{array}{l}\text { Relacionadas às condições sócio, político e } \\
\text { econômicas do aluno. }\end{array}$} \\
\hline Falta de tempo para estudar & \\
\hline Carga horária semanal de trabalho & \\
\hline Deslocamento até o polo de ensino & \\
\hline Dificuldades de acesso à Internet & \\
\hline \multicolumn{2}{|c|}{ Vocação Pessoal } \\
\hline Possuir outro curso de especialização & \multirow{5}{*}{$\begin{array}{l}\text { Relacionadas ao aluno diretamente, ou seja, } \\
\text { aptidão para o curso, interesses pessoais e } \\
\text { prévios do curso. }\end{array}$} \\
\hline Mudança de interesse pessoal ou profissional & \\
\hline Não adaptação à modalidade Educação a Distância & \\
\hline Falta de habilidade para usar as TICs & \\
\hline Desconhecimento prévio a respeito do curso & \\
\hline \multicolumn{2}{|c|}{ Circunstâncias Individuais } \\
\hline Problemas de saúde & \multirow{5}{*}{$\begin{array}{l}\text { Relacionada a circunstâncias que vão além da } \\
\text { condição do aluno no curso, como problemas } \\
\text { familiares, de saúde e financeiros. }\end{array}$} \\
\hline Problemas financeiros & \\
\hline Influência familiar & \\
\hline Mudança de estado civil & \\
\hline Mudança de residência ou cidade & \\
\hline
\end{tabular}

Fonte: Bittencourt e Mercado (2014, p. 477)

As causas internas, vistas no quadro 1, estão ligadas a ações institucionais e podem ser evitadas pelas instituições, diminuindo assim os índices de evasão. Já as causas externas, quadro 2 , estão associados a motivos ligados a vida do estudante fora da instituição de ensino, tendo esta então, pouca possibilidade de atuar para evitar a evasão.

\section{PROCESSOS METODOLÓGICOS: MATERIAIS E MÉTODOS}

A investigação que apresentamos apresenta a natureza de uma pesquisa aplicada que visa descobrir os motivos da evasão em um curso de pós-graduação, ofertado a distância. Quanto a sua abordagem esta é uma pesquisa de cunho quali-quantitativa. Já quanto aos seus objetivos podemos dizer que esta é uma pesquisa exploratória quando “[...] visa aumentar o conhecimento sobre um determinado tema ou assunto [...]" (MALHEIROS, 2011, p. 32) para tornar uma situação mais explícita, no caso desta pesquisa a evasão no curso em questão. Ela também terá como objetivo descrever os motivos que determinam ou contribuem para a evasão dos alunos.
A presente pesquisa classifica-se, quanto ao procedimento técnico utilizado como survey, ou de levantamento, que é um tipo particular de pesquisa social empírica que visa à obtenção de dados ou informações sobre características ou opiniões de determinado grupo de pessoas por meio de um instrumento de pesquisa, usualmente um questionário (FREITAS et al., 2000).

A coleta dos dados foi interseccional, ou seja, realizada em um único intervalo de tempo e com uma amostragem não probabilística por conveniência na qual os participantes escolhidos estão disponíveis para responderem ao questionário. $\mathrm{O}$ público alvo foi formado por alunos desistentes por nota em todas as seis ofertas de um curso de pós-graduação a distância que visa capacitar profissionais/professores para o uso de tecnologias digitais no processo de ensino-aprendizagem, de forma interdisciplinar. Ela é ofertada pelo Instituto Federal do Espírito Santo (Ifes) que atua com EaD desde de 2010.

Como instrumento de coleta de dados foi utilizado um questionário enviado via email pra 334 alunos evadidos, respondido por 66 alunos (19,76\%), sendo que apenas 1 ex-aluno acessou acessou o questionário e se recusou participar da pesquisa. $\mathrm{O}$ 
questionário foi construído com base nas categorias e subcategorias apresentadas nos Quadros 1 e 2. Ele foi composto por 18 questões fechadas e uma questão aberta, elaborado na plataforma gratuita Google Forms, dividido em cinco seções: (1) Termo de Consentimento Livre e Esclarecido; (2) dados gerais; (3) perfil do aluno (4) sobre o curso; (5) causas do abandono/ cancelamento, sendo esta última seção subdividida em causas internas e causas externas ao contexto do curso, podendo o respondente escolher mais de um motivo em cada categoria.

\section{RESULTADOS E DISCUSSÃO}

Iniciamos a análise dos resultados deste trabalho traçando um pequeno perfil dos sujeitos da pesquisa. Em relação à turma da qual os sujeitos fizeram parte temos a seguinte distribuição: $42,6 \%$ participaram da sexta turma, $16,4 \%$ da quinta turma, 9,8\% da quarta turma, 14,8\% da terceira turma, $6,6 \%$ da segunda turma e $9,8 \%$ da primeira turma. Em relação ao gênero, há maior concentração do sexo feminino, com 55\%, enquanto o público masculino totalizou $45 \%$. A maioria (56\%) possui mais de 31 anos, seguido do grupo de 26 a 30 anos (29\%). Deste grupo, em relação à evasão, afirmaram que: $72,7 \%$ abandonaram; 21,2\% cancelaram e 6,1\% reprovaram em alguma disciplina. A seguir serão apresentados e analisados os motivos da evasão apresentados pelos sujeitos da pesquisa, divididos entre causas internas e causas externas.

\subsection{Causas Internas}

As causas internas, associadas à evasão na educação, aqui analisada foram decompostas em 3 (três) categorias - atitude comportamental, motivos institucionais $\mathrm{e}$ didático-pedagógicos, as quais subdividemse em 17 motivos.

Em atitude comportamental, conforme visto no Gráfico 1, destaca-se a didática dos professores seguido pelo contato com o professor.

Gráfico 1: Atitude Comportamental



Fonte: Autoria própria (2018).

As ofertas do curso seguindo as orientações da UAB possuem um professor conteudista e formador responsável pelo planejamento das disciplinas, que não possuem contato direto com os alunos. A relação presencial se estabelece por intermédio dos tutores a distância e presencial. Em função desses resultados, está sendo proposto para as novas ofertas um maior envolvimento dos professores com os alunos.

Em relação aos motivos institucionais, a interação e os meios de comunicações disponíveis no Ambiente Virtual de Aprendizagem (AVA) foram os mais apontados conforme visto no Gráfico 2.

Aqui percebe-se que o ambiente virtual utilizado o Moodle não é suficiente para garantir uma boa interatividade entre os cursistas, assim como com a equipe. $\mathrm{O}$ que demanda da organização do curso repensar as ferramentas de comunicação utilizadas, inclusive abrindo a possibilidade de utilização de ferramentas de comunicação externas ao AVA como a utilização de redes sociais.

Gráfico 2: Motivos Institucionais

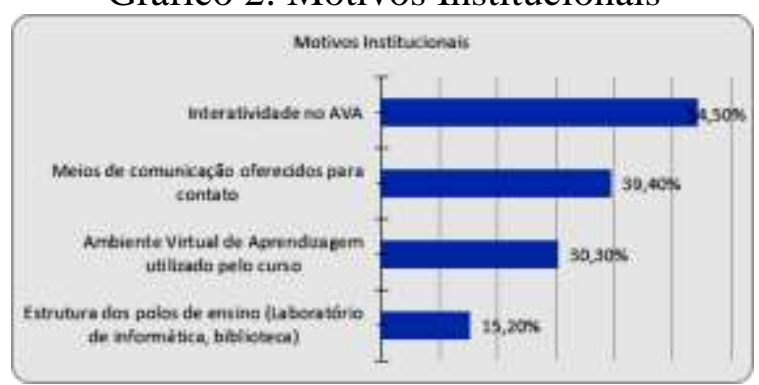

Fonte: Autoria própria (2018).

Entre os requisitos didáticopedagógicos, as duas opções relacionadas às atividades que receberam maior atenção dos 
respondentes foram: complexidade das atividades $(57,7 \%)$ e prazos de entrega das atividades $(53,3 \%)$, conforme vistos no Gráfico 3. Vale destaque que este grupo em relação à carga horária semanal de dedicação ao curso afirma que: $45 \%$ deles dedicaram apenas de 0 a 5 horas semanais ao curso e $30 \%$ demonstraram que dedicaram de 6 a 10 horas.

Gráfico 3: Requisitos Didático-Pedagógicos

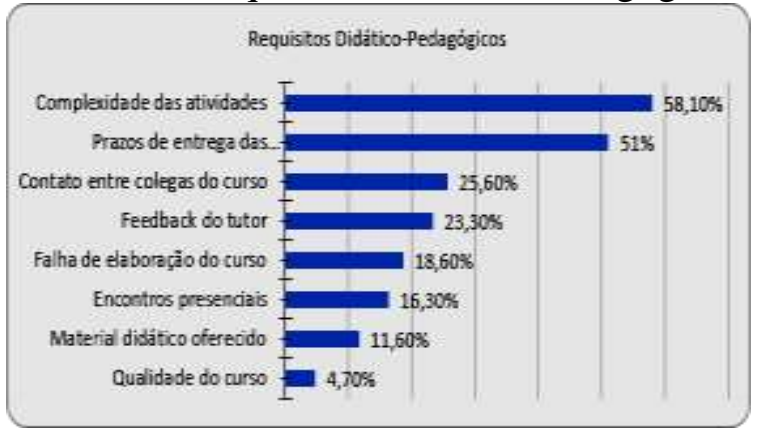

Fonte: Autoria própria (2018).

Embora o curso a distância possibilita autonomia e flexibilidade de horários, também exige o cumprimento, em tempo hábil, das atividades semanais. O tempo de dedicação ao curso $\mathrm{EaD}$ e a organização são essenciais, nesse sentido Netto et al. (2017, n.p) afirmam: "[...] tendo em mente que um curso a distância exige em média de 12 a 15 horas de estudos semanais, ou seja, é necessário um maior tempo de estudo do que o presencial". Para tentar reverter este quadro, para as próximas turmas será realizado um trabalho de conscientização sobre a necessidade de tempo de dedicação ao curso.

\subsection{Causas Externas}

As causas externas estão diretamente ligadas ao estudante antes de entrar na instituição de ensino, ou seja, são referentes aos motivos sociopolítico-econômicos, vocação pessoal e circunstâncias individuais. Nesse contexto, as causas externas foram subdivididas em 3 categorias e 15 possíveis motivos relacionados à evasão.
Os motivos sociopolítico-econômicos foram os que obtiveram o maior número de participantes entre as outras categorias.

Gráfico 4: Motivos SociopolíticoEconômicos

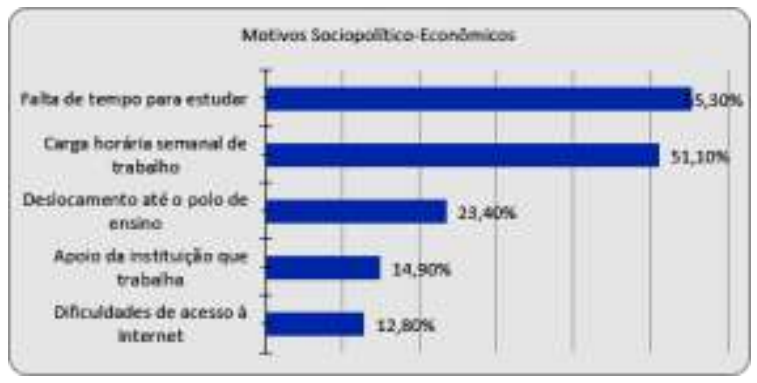

Fonte: Autoria própria (2018).

Segundo o Censo EAD BR (2016), a falta de tempo para estudar é apontada como um dos motivos que ocasionam a evasão discente na educação a distância. Nesta pesquisa, foi o motivo mais indicado pelos participantes como causador da desistência. Este grupo afirma em relação à carga horária de trabalho durante o curso que: $50 \%$ trabalhou mais de 40 horas semanais, seguido de $33,0 \%$ que afirma ter trabalhado entre 20 e 40 horas semanais. Entende-se que tal jornada de trabalho, aliado aos compromissos familiares do público, pois, em sua maioria, os sujeitos da pesquisa são casados, separados ou divorciados $(58 \%)$ e possuíam filhos $(41 \%)$, tende a concorrer diretamente com as atividades escolares exigidas pelo curso. Assim, seria possível associar a falta de tempo como consequência da carga horária semanal de trabalho, no entanto, do ponto de vista de Netto et al. (2017, n.p):

A organização do tempo para os alunos que frequentam cursos na modalidade a distância é fundamental [...] Se uma grande vantagem do aluno EAD é ter livre arbítrio para escolher a hora e local para estudar, pode ser uma desvantagem para quem não consegue estabelecer horários de estudo e regras que estabeleçam uma organização para dedicação ao curso.

A não adaptação à modalidade $\mathrm{EaD}$ é apresentada no Censo EAD.BR (2016) como um dos três principais motivos 
associados à evasão, ao lado da falta de tempo e das questões financeiras. No Gráfico 5, que apresenta as respostas obtidas na categoria vocação pessoal, a não adaptação à modalidade é apontada pelos sujeitos da pesquisa como um fator relacionado à saída do curso $(28,10 \%)$.

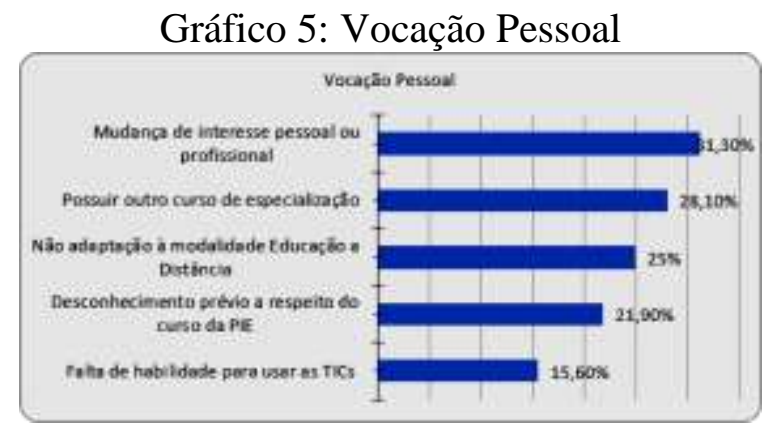

Fonte: Autoria própria (2018).

Esse problema pode ser associado à faixa etária do público majoritário da $\mathrm{EaD}$ e dos participantes desta pesquisa, $36 \%$ na faixa de mais de 35 anos, o qual teve uma escolarização essencialmente convencional. Entretanto, neste trabalho, a falta de habilidades para usar os recursos digitais foi apontada como umas das dificuldades centrais no estudo de Cornelio et al. (2016), motivo com o menor percentual. Porém, a mudança de interesse pessoal $(31,30 \%)$ teve a maior incidência.

As circunstâncias individuais, em muitos casos, fogem ao controle do aluno. Notou-se que foi a causa com menor adesão de respostas. No entanto, houve consideráveis relatos na questão aberta sobre problemas nessa ordem que foram decisivos para o respondente evadir. Conforme o Gráfico 6, os problemas de saúde foram indicados por $43,3 \%$ dos participantes. Como anteriormente mencionado neste trabalho, a evasão motivada por questões financeiras é uma das três principais causas segundo o levantamento do Censo EaD.BR (2016), contudo no levantamento realizado apenas $12,20 \%$ apontaram tal motivo.

Esta pesquisa, embora especifique uma população-alvo de um curso totalmente gratuito de uma instituição pública - sem

custos com mensalidade por parte do aluno considerou a questão financeira.

Gráfico 6: Circunstâncias Individuais

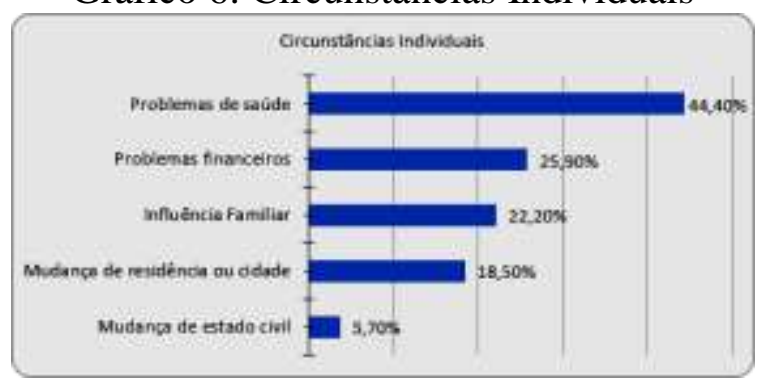

Fonte: Autoria própria (2018).

Logo, constata-se, de acordo com análise das perguntas fechadas as seguintes causas relacionadas à evasão do públicoalvo: falta de tempo para estudar, carga horária semanal de trabalho, complexidade das atividades, prazos de entrega das atividades e didática dos professores. Essas além de apresentarem as maiores taxas nas questões fechadas, também foram apontadas na questão aberta (opcional) como preponderantes pelos participantes da presente pesquisa.

\section{CONCLUSÕES}

A evasão discente embora esteja presente em diversas instituições ao redor do mundo, independentemente do nível de ensino, afeta, sobretudo o desempenho dos cursos da educação a distância, os quais têm despontado como alternativas democráticas ao ensino superior. $\mathrm{O}$ fenômeno da evasão determina o encerramento dos cursos, assim como resulta em ociosidade de profissionais, de materiais e de espaço físico. O problema é agravado em razão do não conhecimento dos motivos da evasão pelas instituições de ensino, principalmente com foco em cursos especificos, como feito neste trabalho.

A fim de determinar os motivos da evasão, no curso em questão, analisando as causas internas e externas propostas por Bittencourt e Mercado (2014), utilizando para isso um questionário como instrumento de coleta de dados enviado via e-mail a 334 alunos de todas as edições do curso, 
obtendo ao final 66 retornos, o que corresponde a $19,76 \%$. Ao final deste trabalho foi possível constatar que tanto as causas internas quanto as externas foram igualmente determinantes na evasão discente no curso estudado.

A questão financeira, embora destacada no Censo EaD.BR (2016), foi pouco apontada pelos respondentes como associada à evasão na presente investigação.

A falta de tempo para estudar foi apontada como a causa que mais influenciou a evasão dos participantes desta investigação. Pode estar associada à carga horária de trabalho, pois a metade declarou exercer atividade remunerada com mais de 40 horas semanais e $75 \%$ dedicaram menos de 10 horas semanais ao curso.

Conclui-se que o fenômeno da evasão prejudica a continuação de programas educacionais, restringindo oportunidades de acesso ao ensino superior. Então, políticas de combate à evasão devem ser implantada nas instituições que oferecem cursos na modalidade, principalmente em instituições públicas, como o caso da instituição objeto desta pesquisa uma vez que a evasão significa desperdício de recursos públicos.

\section{REFERÊNCIAS}

ABBAD, Gardênia; CARVALHO, Renata Silveira; ZERBINI, Thaís. Evasão em curso via internet: explorando variáveis

explicativas. RAE electron, São Paulo, v. 5, n. 2, Dec. 2006. Disponível em:

http://www.scielo.br/scielo.php?script=sci_ arttext\&pid=S1676-

$56482006000200008 \& \operatorname{lng}=$ en\&nrm=iso.

Acesso em: 03 sep. 2019.

ABED - Associação Brasileira de Educação a Distância. Censo EAD.BR: relatório analítico da aprendizagem a distância no Brasil 2017 - [livro eletrônico] Curitiba: InterSaberes, 2018.

ABED - Associação Brasileira de Educação a Distância. Censo EAD.BR: relatório analítico da aprendizagem a distância no
Brasil 2016 - [livro eletrônico] Curitiba: InterSaberes, 2017.

BIAZUS, Cleber Augusto. Sistema de fatores que influenciam o aluno a evadirse dos cursos de graduação na UFSM e na UFSC: um estudo no cursos de Ciências Contábeis. 2004. 203f. Dissertação (Doutorado em Engenharia de Produção) Universidade Federal de Santa Catarina, Florianópolis. Disponível em: https://repositorio.ufsc.br/handle/123456789 /87138. Acesso em: 10 jan. 2019.

BITTENCOURT, Ibsen Mateus; MERCADO, Luís Paulo Leopoldo. Evasão nos cursos na modalidade de educação a distância: estudo de caso do Curso Piloto de Administração da UFAL/UAB. Ensaio: aval.pol.públ.Educ., Rio de Janeiro, v. 22, n. 83, p. 465-504, June 2014. Disponível em: http://www.scielo.br/scielo.php?script=sci_ arttext\&pid=S010440362014000200009\&lng=en\&nrm=iso. Acesso em: 03 sep. 2019.

BITTENCOURT, Ibsen Mateus; MERCADO, Luís Paulo Leopoldo. Problemas Endógenos como Principal Causa de Evasão do Curso Piloto de Administração a Distância da UFAL/UAB. In: $18^{\circ}$ CIAED Congresso Internacional ABED de EaD, 2012, São Luís - MA. Anais do $18^{\circ}$ CIAED - Congresso Internacional ABED de Educação a Distância. 2012. Disponível em: http://www.abed.org.br/congresso2012/anai s/167f.pdf. Acesso em: 03 sep. 2018.

\section{BRASIL. Lei de Diretrizes e Bases da}

Educação Nacional. Lei n. 9394/96 de 20 de dezembro de 1996, Brasília, 1996.

Decreto n. 5.800, de 8 de junho de 2006. Dispõe sobre o Sistema Universidade Aberta do Brasil. 2006.

CORNELIO, Ricardo Antonio; VASCONCELOS, Fernanda Carla Wasner; GOULART, Iris Barbosa. Educação a distância: uma análise estatística dos fatores 
relacionados à evasão e à permanência.

Revista Gestão Universitária na América Latina-GUAL, v. 9, n. 4, p. 26-44, 2016.

FIALHO, Marília Duarte; PRESTES, Emília Maria da Trindade. Evasão escolar no curso de pedagogia da UFPB: na compreensão dos gestores educacionais. Gestão \& Aprendizagem, v. 3, n. 1, p. 4263, 2014.

FREITAS, Henrique et al. O método de pesquisa survey. Revista de Administração da Universidade de São Paulo, v. 35, n. 3, p. 105-112, 2000.

FÁVERO, Rute Vera Maria. Dialogar ou evadir: Eis a questão!: um estudo sobre a permanência e a evasão na educação a distância. 2006. 167f. Dissertação (Mestrado em Psicopedagogia) - Faculdade de Educação, Universidade Federal do Rio Grande do Sul, Porto Alegre. Disponível em:

https://www.lume.ufrgs.br/bitstream/handle/ 10183/14846/000669958.pdf? sequence $=1$.

Acesso em: 03 sep. 2018.

JENSEN, Lauren Fontes; ALMEIDA, Onilia Cristina de Souza de. A correlação entre falta de interatividade e evasão em cursos a distância. In: $\mathbf{1 5}^{\circ}$ CIAED Congresso Internacional ABED de EaD, 2009, Fortaleza - CE. Anais do $15^{\circ}$ CIAED - Congresso Internacional ABED de Educação a Distância. 2009. Disponível em: http://www.abed.org.br/congresso2009/CD/ trabalhos/452009151730.pdf. Acesso em: 03 mar. 2018.

MALHEIROS, Bruno Taranto. Metodologia de pesquisa em educação. Rio de Janeiro: LTC, 276f. 2011.

MOORE; Michael. G, KEARSLEY, Greg. Educação a distância: uma visão integrada. São Paulo: Thonson Learning, 2007.

NETTO, Carla; GUIDOTTI, Viviane; SANTOS, Pricila Kohls dos. A evasão na
EaD: investigando causas, propondo estratégias. In: Congresso CLABES. 2017. Disponível em:

https://revistas.utp.ac.pa/index.php/clabes/ar ticle/view/865. Acesso em: 03 mar. 2018.

OLIVEIRA, Pedro Rodrigues de; OESTERREICH, Silvia Aparecida; ALMEIDA, Vera Luci de. Evasão na pósgraduação a distância: evidências de um estudo no interior do Brasil. Educ. Pesqui., São Paulo, v. 44, e165786, 2018.

Disponível em:

http://www.scielo.br/scielo.php?script=sci arttext\&pid=S1517-

$97022018000100307 \& \operatorname{lng}=$ en $\& n r m=$ iso.

Acesso em: 20 mar. 2018.

REINO, Lucianny Raihanny Alves

Cavalcante et al. Análise das Causas da

Evasão na Educação a Distância em uma Instituição Federal de Ensino Superior. In:

Brazilian Symposium on Computers in Education (Simpósio Brasileiro de Informática na Educação-SBIE). 2015. p. 91.

SILVA FILHO, Roberto Leal Lobo et al. A evasão no ensino superior brasileiro.

Cadernos de pesquisa, v. 37, n. 132, p. 641-659, 2007.

TINTO, Vincent. Dropout from higher education: a theoretical synthesis of recent research. Review of Educational

Research, Washington, v.45, n.1, p.89-125, 1975.

VASCONCELOS, Sérgio Paulo Gomes de. Educação a Distância: histórico e perspectivas. Universidade do Estado do Rio de Janeiro (UERJ). Disponível em: http://www.filologia.org.br/viiifelin/19.htm. Acesso em: 04 jun. 2018.

WOODLEY, A.; SIMPSON, O. Evasão: o elefante na sala. In: ZAWACKI-RICHTER, O.; ANDERSON, T. (Org.). Educação a distância online: construindo uma agenda de pesquisa. São Paulo: Artesanato Educacional, 2015. p. 473-498. 